\title{
TRANSFORMASI MODEL BISNIS BAITUL MAAL WAL TAMWIL MELALUI DESIGN MODEL PATFORM
}

\author{
Almun Wakhida Candra \\ Universitas Muhammadiyah Sidoarjo \\ Bayu Wardhana \\ Universitas Muhammadiyah Sidoarjo \\ Eris Dwi Retno \\ Universitas Muhammadiyah Sidoarjo \\ Lela Monika \\ Universitas Muhammadiyah Sidoarjo \\ Ngafiatul Ngulfa \\ Universitas Muhammadiyah Sidoarjo \\ Risky Sari Rahayu \\ Universitas Muhammadiyah Sidoarjo
}

\begin{abstract}
Today's technology has experienced developments where all lines of people's lives have used technology. Technology has entered all sectors of the economy, including the Islamic financial sector, which is called financial digitization. But on the other hand, there are still financial institutions that have not fully implemented technology in their business models or in their services. Therefore, in this study, innovations regarding the application of technology in the Baitul Maal Wal Tamwil will be discussed.
\end{abstract}

Kata Kunci : Baitul Maal Wal Tamwil,Business Model Canvas,Platform

\begin{abstract}
Abstrak
Teknologi saat ini telah mengalami perkembangan dimana semua lini kehidupan masyarakat telah menggunakan teknologi. Teknologi telah masuk kedalam semua sector ekonomi termasuk kedalam sektor keuangan syariah yang dinamakan digitalisasi keuangan. Tetapi disisi lain masih terdapat lembaga keuangan yang belum sepenuhnya menerapkan teknologi dalam model bisnisnya atau dalam pelayanannya. O leh karena itu didalam penelitian ini akan dibahas inovasi mengenai penerapan teknologi pada baitul maal wal tamwil.
\end{abstract}

Kata Kunci : Baitul Maal Wal Tamwil,Business Model Canvas,Platform

\section{Pendahuluan}

Penelitian ini didasari oleh dua isu utama yaitu manfaat besar dari adanya digitalisasi keuangan dimana akan mendorong kemudahan dalam aksebilitas produk layanan keuangan (Haryati, 2019). Kedua adalah penerapan teknologi pada lembaga keuangan baitul maal wal tamwil yang masih belum diterapkan secara maksimal (Winardi, 2012). 
Teknologi pada saat ini cukup berkembang pesat dimana saat ini sudah ditandai dengan masuknya era revolusi industry 4.0. Revolusi industry ini membawa perubahan besar pada semua sektor kehidupan manusia tak terkecuali sektor perkembangan teknologi dan proses produksi dalam hal kegiatan ekonomi (Pratiwi, 2019). Perkembangan teknologi ini banyak membawa banyak perubahan dalam segi bisnis,keberhasilan dalam bisnis saat ini sangat dipengaruhi seberapa cepat perusahaan tersebut dapat merespons perubahan teknologi tersebut (Abdus Salam, 2018).Oleh karena itu agar bisnis dalam suatu perusahaan dapat berkembang pesat maka perusahaan harus dapat mengikuti alur perubahan teknologi tersebut.

Saat ini merupakan era dimana teknologi telah masuk kedalam semua lini sektor atau bisa disebut dengan digitalisasi dengan ditandai oleh semakin banyaknya pengguna internet (Kominfo.go.id, 2018) . Pada tahun 2018 saja pengguna internet masyarakat Indonesia mencapai 64,8 persen atau dengan kata lain sebanyak 171,17 juta jiwa menggunakan internet (APJII, 2018).

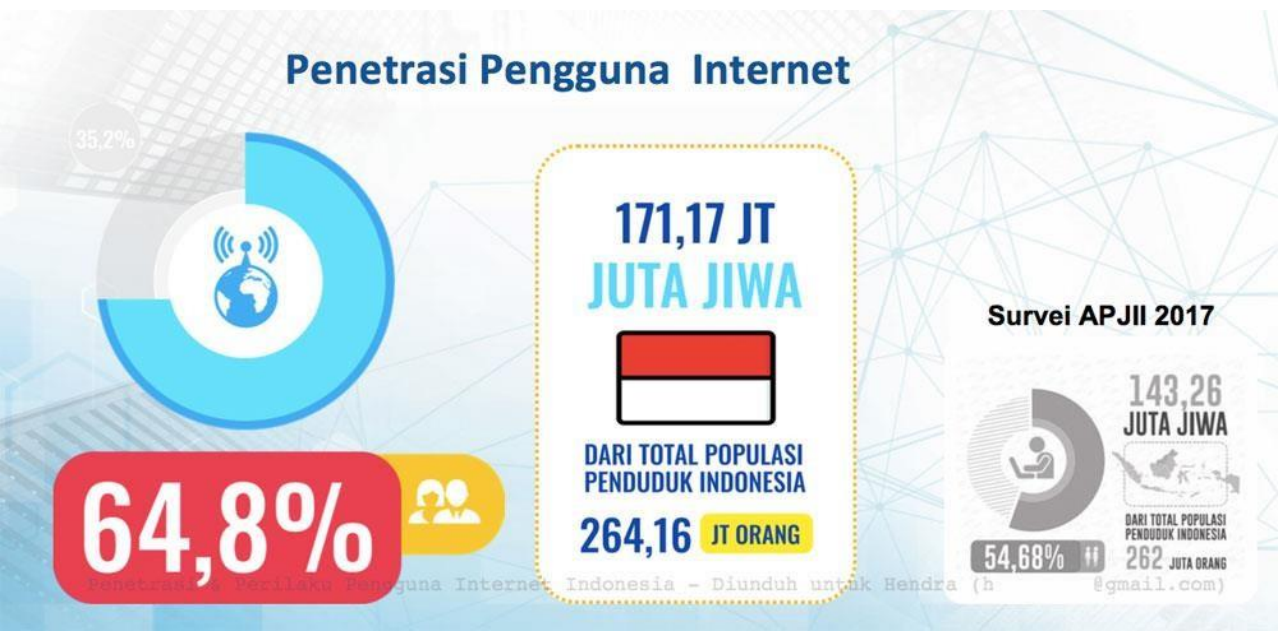

Sektor keuangan saat ini juga telah masuk kedalam digitalisasi. Adanya digitalisasi ini akan berdampak besar bagi sektor keuangan khususnya lembaga keuangan, sebagai contoh saat ini bank syariah saat ini tengah intens dalam menerapkan teknologi pada bisnis mereka dengan tujuan untuk mempermudah layanan transaksi keuangan kepada nasabah (Ellyanawati, 2018). Bisa dikatakan teknologi saat ini memegang peranan penting dalam lembaga keuangan. Maju atau tidaknya lembaga keuangan ditentukan oleh penerapan teknologi selain itu apabila lembaga keuangan tidak menerapkan teknologi ini maka lembaga keuangan tersebut untuk maju dan berkembang (Karamoy, 2018). Manfaat yang dapat dirasakan oleh lembaga keuangan apabila menerapkan teknologi ini adalah dapat meningkatkan akan literasi keuangan khususnya bagi masyarakat yang tinggal didaerah terpencil yang sulit akan jangkauan layanan keuangan (Rusydiana, 2019). Pada saat ini dunia telah memasuki era digitalisasi dimana dalam semua lini sektor telah melibatkan penggunaan 
teknologi untuk memudahkan setiap pengerjaanya. Tak terkecuali sektor keuangan yang tengah masuk dalam era digitalisasi, hal ini ditunjukkan dengan semakin bermunculan Financial Technology (Fintech). Menurut data yang dihimpun dari Otoritas Jasa Keuangan (OJK) jumlah fintech yang terdaftar dan berizin pada bulan agustus 2019 adalah sebanyak 127 fintech (Keuangan, 2019). Maraknya fintech yang terus bermunculan mendorong bank pada saat ini berubah dalam bentuk fintech hal ini ditujukan untuk menciptakan pasar baru dan memungkinkan terciptanya layanan baru berbasis teknologi (Urbach, 2017). Didalam dunia perbankan saat ini penggunaan teknologi telah mengalami perkembangan yang begitu signifikan. Sebagai contoh adalah dalam pelayanan jasa perbankan saat ini yang semula dilakukan dengan cara konvensional beralih dengan layanan berbasis teknologi yang hal ini justru akan berdampak pada segmen pasar baru dan akan memunculkan produk produk baru berbasis teknologi (Julapa Jagtiani, 2018). Bisa dikatakan fintech sendiri memainkan peranan penting dalam sector ekonomi di lain hal fintech juga membentuk sebuah lanskap keuangan dan perbankan yang baru dengan berbasis teknologi (Julapa Jagtiani, 2018).

Salah satu lembaga yang dapat melakukan transformasi ke industri financial technology adalah Baitul Mal Wa Tamwil. Baitul Maal Wa Tamwil merupakan lembaga keuangan syariah non bank yang bergerak sesuai dengan prinsip syariah memiliki dua fungsi yaitu untuk fungsi komersial dan sosial (Referensi coy). Jumlah Baitul Maal Wa Tamwil diseluruh Indonesia telah mecapai 5000 yang menyediakan pelayanan masyarakat dari yang paling rendah hinggan menengah (Master P lan Arsitek Keuangan Syari'ah) (Referensi coy). Penerapan teknologi sangat perlu diterapkan pada lembaga baitul maal wal tamwil karena dapat mempermudah system operasional baitul maal wal tamwil tersebut sebagai contoh adalah dengan adanya penerapan teknologi ini memudahkan baitul maal wal tamwil dalam pengelolaan data data keuangan (Zaliluddin, 2016). Selama ini sudah banyak baitul maal wal tamwil menerapkan teknologi ini tetapi masih terdapat kendala dalam penerapannya terutama dalam hal infrastruktur belum sepenuhnya diterapkan sehingga proses operasional baitul maal wal tamwil tersebut mengalami gangguan (Apriyanti, 2018).

Berdasarkan latar belakang yang telah dipaparkan sebelumnya, menimbulkan berbagai pertanyaan untuk mencari solusi alternatif yang inovatif. Salah satunya adalah menciptakan solusi dan inovasi yaitu menciptakan suatu design model platform yang dikhususkan untuk baitul maal wal tamwil agar dapat bertransformasi dari operasional dengan menggunakan system konvensional beralih kepada operasional berbasis digital. 


\section{Tinjauan Pustaka}

\section{Baitul Maal Wal Tamwil}

Terdapat banyak lembaga keuangan syariah yang terdapat diindonesia salah satunya adalah baitul maal wal tamwil. Baitul Maal Tamwil (BMT) berasal dari bahasa arab yang tersusun dari dua suku kata yakni bayt al- mal dan bayt altamwil. Bayt al-mal sendiri tersusun dari dua suku kata yaitu bayt dan al mal. Bayt sendiri diartikan sebagai rumah sedangkan al-mal diartikan sebagai harta atau kekayaan (Permata Cita,2017). Sejarah baitul maal wal tamwil sendiri lahir atas realisasi rekomendasi dari adanya $\mathrm{S}$ ilaturahmi Kerja Nasional (SILAKNAS) Ikatan Cendekiawan Muslim Indonesia yang diselenggarakan pada tahun 1994 (Febrian \& Mardian, 2017). Berdirinya lembaga keuangan ini tak terlepas dari eksistensi Bank S yariah pertama di Indonesia yaitu bank syariah muamalat yang telah beroprasi sejak tahun 1992 tetapi belum dapat memberikan dampak bagi masyarakat luas terutama mereka masyarakat pengusaha mikro. Dalam menjalankan bisnisnya baitul maal bukan hanya berfokus mencari keuntungan tetapi juga menjalankan kegiatan sosial seperti mengumpulkan dana infaq,sedekah dan zakat dan wajib menyalurkan kepada pihak yang membutuhkan (Endratno, 2017).

Hadirnya baitul maal wal tamwil membawa dampak tersendiri khususnya kepada masyarakat kecil karena dapat memberikan solusi permodalan kepada usaha mikro kecil yang bertujuan juga sebagai pengentasan kemiskinan (Wijiharta, 2019). Bisnis yang dikembangkan baitul maal wal tamwil sama seperti halnya lembaga keuangan perbankan yaitu menghimpun dana dari nasabah dan menyalurkannya kepada sektor ekonomi yang halal sekaligus menguntungkan selain itu baitul maal wal tamwil berpotensi mengembangkan bisnisnya di sektor riil disamping masih belum sepenuhnya bank dapat terjun dalam sektor tersebut (Abdilla, 2019).

\section{Business Model Canvas}

Model bisnis dapat diterapkan sebagai alat konseptual yang digunakan perusahaan dalam menciptakan,memberikan dan menangkap nilai dari pelanggan (Wuest, 2019). Business model canvas merupakan suatu konsep yang digunakan untuk menggambarkan model bisnis dari suatu bisnis yang dikembangkan oleh ostelwalder dan pigneur. Tujuan dibuatnya model bisnis ini adalah agar setiap orang memiliki persepsi yang sama terhadap model bisnis tersebut (Hornunga, 2018). Didalam model business model canvas sendiri terdapat Sembilan elemen yang mewakili konten dalam suatu bisnis (S heahan, 2018). Business model canvas sendiri terdiri dari 
Sembilan elemen yaitu key partners,key activities, value propositions,customer relationships,customer segments, key resources,channels, cost structure, revenue streams.

\section{Platform}

Kata platform menurut kamus besar bahasa Indonesia adalah berarti pentas atau panggung, arti tersebut dapat diartikan sebagai tempat untuk menampilkan se suatu (Wirawan, 2017). P latform merupakan sebuah wadah tempat untuk bertemunya pelanggan atau dua pelanggan selain itu platform didalam platform ini juga seabagai wadah untuk saling berinteraksinya antara pelanggan tersebut (Maika, 2017). Platform yang bisa dikatakan sukses adalah platform yang mampu mengatasi sebuah siklus yang baik. Platform di dalam prespektif penelitian ini adalah sebuah model bisnis yang me nghubungkan beberapa sisi yaitu sisi produsen dan konsumen yang bertujuan untuk memberikan ruang interaksi dengan menyediakan sebuah infrastruktur yang menghubungkan keduanya. Didalam platform terdapat berbagai fasilitas jika terjadi permasalahan diantara para pelaku bisnis tersebut sehingga memungkinkan interaksi tersebut berjalan dengan lancar. Sementara dalam penelitian ini platform yang dimaksud adalah platform web yang dapat memberikan informasi kepada masyarakat tentang pembayaran online yang disediakan oleh Baitu Mal Wa Tamwil (Rachma \& Wibisono, 2018).

\section{Metode Penelitian}

Pada penelitian ini menggunakan pendekatan penelitian metode kualitatif dimana pada penelitian ini banyak mendeskripsikan tentang peran manajemen resiko reputasi dalam menciptakan prespektif positif masyarakat pada lembaga keuangan baitul maal wa tamwil (BMT). Metode kualitatif adalah suatu metode penelitian secara luas menggunakan pendekatan interpretatif dan kritis pada masalah-masalah sosial (gumilar, 2005). Pada penelitian kualitatif memfokuskan dirinya pada makna subjektif, pendefinisian, metafora, dan deskripsi pada kasus- kasus yang spesifik. Penelitian kualitatif berusaha menjangkau berbagai aspek dari dunia sosial termasuk atmosfir yang membentuk suatu objek amatan yang sulit ditangkap melalui pengukuran yang presisif atau diekspresikan dalam angka. Dengan demikian, penelitian kualitatif lebih bersifat transendental, termasuk di dalamnya memiliki tujuan menghilangkan keyakinan palsu yang terbentuk pada sebuah objek kajian. Penelitian kualitatif berusaha memperlakukan objek kajian tidak sebagai objek, namun lebih sebagai proses kreatif dan mencerna kehidupan sosial sebagai sesuatu yang "dalam" dan penuh gelagak. 
Sebelum penelitian ini dilakukan tentunya dibuat sebuah rancangan penelitian yang berguna untuk penelitian. Tahapan awal ada lah mengidentifikasi permasalahan yang terjadi seperti bagaimana prespektif masyarakat terhadap baitul mal wal tamwil. $\mathrm{P}$ roses identifikasi ini didapatkan dari proses observasi pada objek tertentu. Objek observasi pada penelitian ini terdiri dari dua jenis yaitu baitul maal wal tamwil dan masyarakat. Setelah melakukan observasi maka hal selanjutnya adalah membaca penelitian dan referensi yang ada maka ditemukanlah sumber permasalahan mengenai pengukuran tingkat penerapan teknologi pada baitul maal wal tamwil.

Didalam penelitian tentunya dibutuhkan suatu objek penelitian yang berguna dalam kegiatan studi kasus. Menurut Spradley dalam (Sugiyono, 2014). Objek penelitian adalah situasi kondisi social yang terdiri dari beberapa unsur-unsur yaitu antara pelaku dan peristiwa alam yang dapat diamati.O leh karena itu didala $\mathrm{m}$ penelitian ini mengenai permasalahan klasik yang dialami oleh umkm dïndonesia.

Awal mula untuk mencari data yang diperlukan maka dibuatlah kerangka berpikir mengenai penelitian apa yang akan dilakukan dan objek yang akan diteliti. Dalam penelitian ini data dikumpulkan dari beberapa penelitian yang telah dilakukan dan data yang diterbitkan oleh lembaga instansi terkait seperti Otoritas Jasa Keuangan (OJK),Bank Indonesia dan lainya.

Pada penelitian ini menggunakan analisis data kualitatif yang artinya adalah menjelaskan mengenai data-data yang berasal dari sebuah penelitian. Tahapan selanjutnya adalah tahapan analisis data dan mulai mencari sumber permasalahan dan mencari solusi yang dapat ditawarkan.

\section{Pembahasan}

\section{Peran Baitul Maal Wal Tamwil}

Baitul maal wal tamwil sendiri berasal dari kata Balai Unit Mandiri Terpadu atau dalam istilah bahasa arab disebut dengan Baitul Maal Wal Tamwil yang merupakan suatu lembaga keuangan mikro syariah yang menjalankan usahanya bedasarkan atau berprinsip pada nilai- nilai syariah. Baitul maal wal tamwil dikenal masyarakat luas dengan sebutan sebagai lembaga keuangan mikro syariah yang fungsi utama baitul maal wal tamwil adalah melakukan penyaluran pembiayaan umkm tidak heran jika nasabah pembiayaan baitul maal wal tamwil untuk sektor lending adalah sebagian besar para pelaku umkm. Selain itu melalui baitul maal wal tamwil dapat memberikan dampak positif bagi para nasabah karena melalui bmt ditanamkan nilai nilai spiritual (Oktafia, 2014). Diindonesia juga dikenal dengan adanya koperasi syariah lalu timbul suatu pertanyaan apa perbedaan dari koperasi syariah dengan baitul maal wal 
tamwil? Secara system operasional baitul maal wal tamwil dengan koperasi syariah tidak ada perbedaan sedangkan apabila ditinjau dari sudut badan hukum baitul maal wal tamwil dan koperasi syariah juga sama yaitu berbadan hukum koperasi dalam segala kegiatan operasional kedua lembaga kaungan tersebut (Yusar Sagara, 2016). Dalam prespektif hukum yang berlaku kedua lembaga keuangan ini dinaungi oleh Undang-Undang No 17 Tahun 2013 yang isinya menyatakan bahwa kedudukan baitul maal wal tamwil sama halnya dengan koperasi (Murdiana, 2016).

Peranan baitul maal wal tamwil terhadap perekonomian tidak bias dipandang sebelah mata. Melalui baitul maal wal tamwil ini sektor usaha usaha kecil dapat termodali. Akan tetapi kiita tahu bahwa sepertiga UMKM yang ada di Indonesia sebanyak $36 \%$ masih belum mendapatkan permodalan dan fakta yang mengejutkan adalah 49 juta UMKM masih belum mendapatkan permodalan. Pernyataan tersebut diperkuat dengan pernyataan dari perusahaan jasa konsultan internasional Pricewaterhouse Coopers (PwC) yang menyebutkan, 74\% Usaha Mikro, Kecil dan Menengah (UMKM) di Indonesia belum mendapat akses pembiayaan. Hal ini bisa menjadi peluang bagi perusahaan teknologi pinjaman (fintech lending) di Indonesia. Dalam studi bertajuk 'Indonesia's Fintech Lending: Driving Economic Growth Through Financial Inclusion', PwC menyampaikan bahwa pemahaman UMKM terkait inklusi keuangan masih rendah. Hal itu menjadi salah satu penyebab $74 \%$ UMKM belum memiliki akses pembiayaan (Katadata, 2019).

Saat ini bentang pasar dan pasar potensial di industri Fintech masih sangat luas terutama di sektor UMKM. Faktanya 49 juta UMKM masih belum bisa dibiaya oleh perbankan. Masih terdapat gap sebesar Rp. $988 \mathrm{~T}$ dalam pengembangan pembiayaan pada segment UMKM (Wijaya, 2017). Sedangkan pada tahun 2017 dari 56,4 juta UMKM, sebanyak 76,1\% memperoleh pembiayaan dari bank dan 23,9\% mengakses dari non-bank, termasuk koperasi. Dengan demikian dapat disimpulkan bahwa UMKM sangat membutuhkan pendanaan dalam operasionalnya. (Tedjasuksmana \& Nagel, 2018)

Dari peran Baitul Mal Wa Tamwil (BMT) yaitu menghimpun, mengelola dan menyalurkan dana maka dapat menjadi solusi sebagai pemodal untuk membantu perkemabangan UMKM di Indonesia. Penerapan teknologi financial (F intech) sangat perlu diterapkan pada lembaga Baitul Maal wal Tamwil (BM T) karena dapat mempermudah system operasional dan memperluas pasar baitul maal wal tamwil (BMT) (Zaliluddin, 2016) terutama pada sector UMKM yang mengalami kesulitan pada pemodalan untuk mengembangkan usahanya.

Untuk itu lembaga keuangan seperti BMT harus mengikuti perkembangan zaman, seperti mengikuti perkembangan layanan yang semakin canggih 
Almun Wakhida Candra: Transformasi Model Bisnis... 273

dengan berbazis teknologi, dengan cara memenuhi kebutuhan masyarakat dalam menyediakan layanan yang mudah dan cepat. Sehingga dapat memberikan dampak poditif terhadap pertumbuhan keuangan berbasis syariah, karena mampu memberikan layanan sesaui dengan kebutuhan masyarakat dengan memberikan manfaat yang banyak dan mudah.

Dengan menerapkan fintech (financial technology) pada Baitul mal wal Tamwil (BMT) seperti di atas, maka akan berpengaruh terhadap minat masyarakat dalam menggunakan layanan keuangan berbasis teknologi atau fintech. Dalam hal ini fintech bisa memberikan layanan dengan syarat yang lebih mudah dan efisien dalam melakukan transaksi dengan Baitul Mal wal Tamwil (BMT). F ungsi BMT sebagai lembaga intermediasi masih belum mampu menjangkau kebutuhan masyarakat yang tinggal di daerah terpencil. Masyarakat tidak mau berbelit dengan prosedur kekhawatiran atau tidak percaya diri ketika hendak bertemu dengan orang bank (Ansori, 2019).

\section{Business Model Canvas Platform Baitul Maal Wal Tamwil}

Business modal canvas merupakan suatu frame work untuk menggambarkan suatu model bisnis dari suatu platform. Business model canvas ini terdiri dari 9 element atau 9 blok yang me nggambarkan suatu kerangka bisnis dalam suatu bisnis. P latform baitul maal wal tamwil ini menggunakan analisa business model canvas untuk menganalisa model bisnis dari platform ini. Sembilan elemen dari business model canvas ini adalah sebagai berikut:

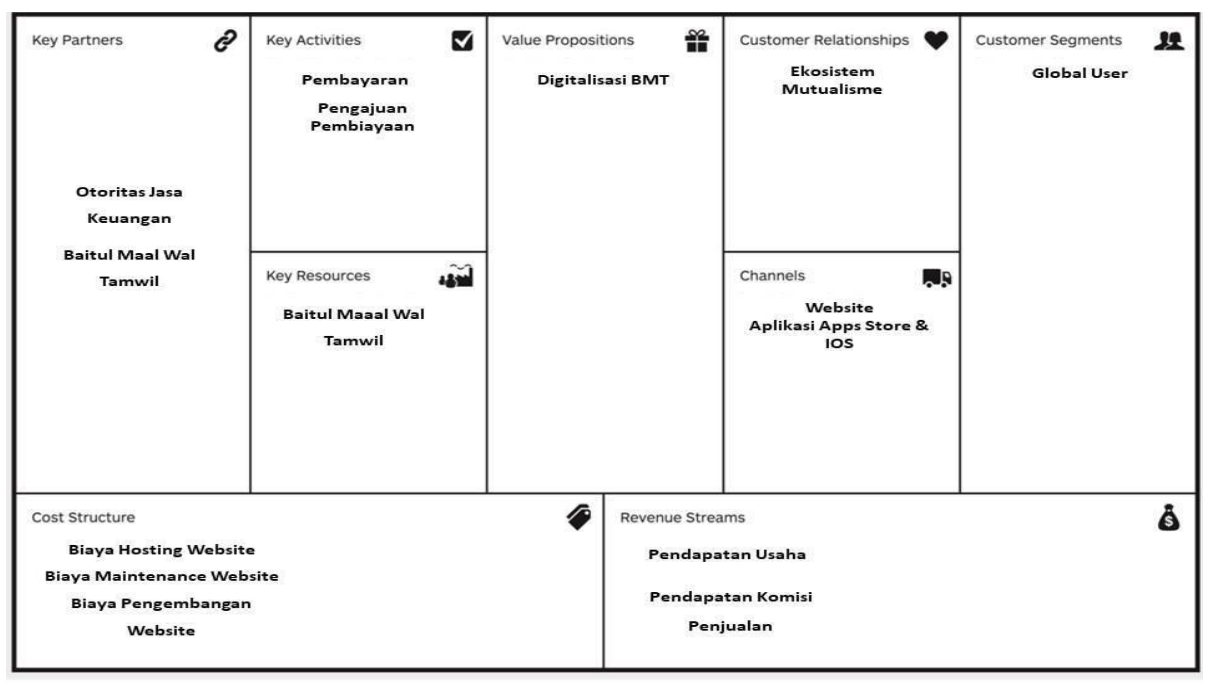

1. Patner Utama (Key Partners)

Platform ini menggandeng dalam platform ini adalah otoritas jasa keuangan selaku pihak yang membuat regulasi lembaga keuangan dan pihak baitul maal wal tamwil 
274 | AT-TAWASSUTH:Jurnal Ekonomi Islam, Volume VI No. II

Juli-Desember 2021: 266 - 277

yaitu lembaga yang akan diajak bekerjasama untuk bertransformasi kedalam bentuk digital.

2. Kegiatan Utama (Key Activities)

Kegiatan utama yang dilakukan dalam konsep platform baitul maal wal tamwil ini adalah pembayaran. Pembayaran ini meliputi pembayaran air,listrik atau sama halnya dengan produk mobile banking selain itu platform ini juga berfungsi untuk nasabah apabila mengajukan pembiayaan.

3. Nilai Preposisi (Value Preposition)

Nilai yang didapat dari platform ini adalah merubah model pelayanan dari baitul maal wal tamwil yang semula dengan cara konvensional ke dalam bentuk digital.

4. Hubungan Konsumen (Customer Relationships)

Hubungan yang timbul dari platform ini antara nasabah dan baitul maal wal tamwil adalah hubungan yang saling menguntungkan atau dengan kata lain ekosistem muatualisme.

5. Segmen Pelanggan (Customer Segments)

Segmen pelanggan pada platform ini adalah global user atau seluruh masyarakat baik masyarakat muslim atau masyarakat non muslim sehingga jangkauan pasar platform ini begitu luas.

6. Sumber Utama (Key Resources)

Sumber utama atau pihak yang akan mengoperasikan platform ini adalah baitul maal wal tamwil. Pihak baitul maal wal tamwil akan mengoprasikan platform ini untuk melayani nasabah.

7. Chanel (Channels)

Chanel yang menghubungkan dalam model bisnis ini adalah platform aplikasi adalah paltfom aplikasi ios. Melalui platform ini diharapkan dapat menghubungkan nasabah dan baitul maal wal tamwil.

8. Struktur Biaya (Cost Structure)

Biaya yang dikeluarkan dalam model bisnis ini adalah pembuatan platform dan biaya pengembangan platform. Biaya ini merupakan biaya yang harus dikeluarkan.

9. Aliran Pendapatan (Revenue Structure)

Pendapatan yang didapat dalam model bisnis ini adalah pendapatan usaha dan komisi penjualan dimana didapatkan dari penjualan produk produk pemabayaran.

\section{Kesimpulan}

Teknologi pada saat ini cukup berkembang pesat dimana saat ini sudah ditandai dengan masuknya era revolusi industry 4.0. Revolusi industry ini membawa perubahan 
Almun Wakhida Candra: Transformasi Model Bisnis... 275

besar yang berdampak pada semua sektor kehidupan manusia tak terkecuali sektor perkembangan teknologi dan proses produksi dalam hal kegiatan ekonomi. Perkembangan teknologi ini banyak membawa banyak perubahan dalam segi bisnis,keberhasilan dalam bisnis saat ini sangat dipengaruhi seberapa cepat perusahaan tersebut dapat merespons perubahan teknologi tersebut. Oleh karena itu agar bisnis dalam suatu perusahaan dapat berkembang pesat maka perusahaan harus dapat mengikuti alur perubahan teknologi tersebut.

Diharapkan dengan adanya platform ini, dapat membantu berkembangnya BMT di Indonesia. Karena BMT memiliki dampak yang cukup besar terhadap perkembangan perekonomian di Indonesia.

\section{Daftar Pustaka}

Abdilla, N. Y. (2019). STRATEGI SUSTAINABILITAS PEMBIAYAAN BAITUL MAAL WAT TAMWIL (BMT) DI KOTA PADANG. Jurnal Menara Ilmu, 13(2), $102-114$.

Abdus Salam. (2018). Inklusi Keuangan Perbankan Syariah Berbasis Digital-Banking: Optimalisasi dan Tantangan. Jurnal Ekonomi Dan Perbankan Syari'ah, 10(1), 63. https:/doi.org/10.24235/amwal.v10i1.2813

Ansori, M. (2019). PERKEMBANGAN DAN DAMPAK FINANCIAL TECHNOLOGY (FINTECH) TERHADAP INDUSTRI KEUANGAN SYARIAH DI JAWA TENGAH. Jurnal Study Keislaman, 5.

APJII. (2018). BULETINAPJIIEDISI23April2018 pengguna internet.pdf.

Apriyanti, B. W. F. F. (2018). Penyusunan Strategi Digital dengan Pendekatan Ward dan Peppard serta Architecture Delivery Pada TOGAF versi 9 pada BMT KAS. Applied Information Systems and Management (AISM), 1(1), 63-67.

Ellyanawati, N. (2018). Analisa Perkembangan Jumlah Outlet Kantor Cabang dan Kebutuhan Frontliners di Era Digital Banking (Studi kasus di Bank Syariah Anak Perusahaan dan UUS Bank BUMN di Yogyakarta). Jurnal Iqtisad, 5(2), 1-13. https//doi.org/10.31942/iq. v5i2.2547

Endratno, S. (2017). Peran Baitul Maal Wa Tamwil (Bmt) Dalam Meningkatkan

Kinerja Usaha Rumah Tangga Di Purwokerto. Jurnal Keuangan Syariah, 2(1), 110.

Febrian, R., \& Mardian, S. (2017). Penerapan PSAK NO. 102 Atas Transaksi Murabahah: Studi Pada Baitul Maal Wa Tamwil Di Depok, Jawa Barat. Journal of Islamic Economics and Business, 2(1), 19-40. https//doi.org/10.24042/febi.v2i1.943

gumilar. (2005). metode penelitian kualitatif. Metode Penelitian, 01.

Haryati, A. S. P. (2019). DIGITALISASI KEUANGAN PADA SUPPLY CHAIN AGRIBISNIS PADI DI MALANG RAYA, JAWA TIMUR, INDONESIA FINANCIAL. Jurnal Ekonomi Pertanian Dan Agribisnis, 3(1), 118-127.

Hornunga, M. U. K. O. P. (2018). Airline categorisation by applying the business model canvas and clustering algorithms. Journal of Air Transport Management, 3(1), 175-192. https//doi.org/10.1016/j.jairtraman.2018.04.005

Julapa Jagtiani. (2018). Fintech: The Impact on Consumers and Regulatory Responses. 
276 AT-TAWASSUTH:Jurnal Ekonomi Islam, Volume VI No. II

Juli-Desember 2021: 266 - 277

Journal of Economics and Business, 2(1), 1-6.

https:/doi.org/10.1016/j.jeconbus.2018.11.002

Karamoy, J. J. . T. G. . P. (2018). Ipteks Informasi Biaya Dalam Penggunaan Produk EChannel Pada Bank Rakyat Indonesia (Persero) Tbk. Jurnal Ipteks Akuntansi Bagi Masyarakat, 2(02), 479-484. https//doi.org/10.32400/jiam.2.02.2018.21813

Katadata. (2019). No Title.

Kominfo.go.id. (2018). No Title.

Maika, M. R. (2017). MODEL EKONOMI BERBAGI "Mobile-SECO" (PLATFORM MULTI-SIDED MARKETS) SEBAGAI EKOSISTEM SOSIO -EKONOMI ISLAMI. Jurnal Ekonomi Dan Bisnis Islam, 12(2), 47. https:/doi.org/10.18860/iq. v12i2.3946

Murdiana. (2016). Menggagas Payung Hukum Baitul Maal Wal Tamwil (BMT) Sebagai Koperasi Syariah Dalam Bingkai Ius Constituendum. Jurnal Penelitian, 2(1), 271294.

Oktafia, R. (2014). PERANAN BAITUL MAAL WATTAMWIL (BMT) TERHADAP UPAYA PERBAIKAN MORAL MASYARAKAT DI KAWASAN DOLLY SURABAYA. Jurnal An-Nisbah, 01(01), 120-137.

PermataCita, D. S. (2017). PERAN KREDIT MODAL USAHA BAITUL MAAL WAT TAMWIL (BMT) DALAM PENINGKATAN PENDAPATAN RUMAH TANGGA MISKIN DESA MOTONG KECAMATAN UTAN. Jurnal Tambora, 2(3), 1-8.

Pratiwi, A. P. D. (2019). Revolusi Industri 4.0: Desain Perkembangan Transaksi dan Sistem Akuntansi Keuangan Agung. Jurnal Ilmu Manajemen Dan Akuntansi Terapan (JIMAT), 10(1), 86-96.

Rachma, N., \& Wibisono, A. (2018). Pemetaan Model Bisnis Public E-Marketplace di Indonesia Dengan Menggunakan Platform Design Toolkit. TEKNIK ITS, 7(1), 149-154.

Rusydiana, I. N. S. (2019). Digitalisasi Keuangan Syariah Menuju Keuangan Inklusif: Kerangka Maqashid Syariah. Jurnal Ekonomi, Keuangan, Perbankan Dan Akuntansi, 11(1), 55. https//doi.org/10.35313/ekspansi.v11i1.1205

Sheahan, S. F. K. T. C. J. N. (2018). Comparing how entrepreneurs and managers represent the elements of the business model canvas. Journal of Business Venturing Insights, 9(2), 65-74. https://doi.org/10.1016/j.jbvi.2018.02.004

Sugiyono. (2014). Metode Penelitian Pendidikan Pendekatan Kuantitatif, Kualitatif, dan $R \& D$. Bandung: Alfabeta.

Tedjasuksmana, B., \& Nagel, P. J. F. (2018). BANK KOPERASI dan FINANCIAL TECHNOLOGY: LEMBAGA dan INOVASI PEMBERDAYAAN OPERASIONAL KEUANGAN UMKM MEMASUKI 2025 PASCA ACFTA ( ASEAN China Free Trade Area ), (2017), 157-162.

Wijiharta. (2019). Pemetaan Permasalahan BMT (Baitul Mal Wat Tamwil): Pendekatan Teori Manajemen Strategi Environmental Scaning. Jurnal Ekonomi \& Perbankan Syariah, 6(1), 79-90. https://doi.org/10.19105/iqtishadia.v6il.2193

Winardi, S. (2012). PENGGUNAAN KERANGKA KERJA COBIT UNTUK MENILAI PENGELOLAAN TEKNOLOGI INFORMASI DAN TINGKAT PELAYANAN (STUDI KASUS PADA BMT 'X' YOGYAKARTA). Jurnal Teknologi Informasi, 7(1), 53-62.

Wirawan, H. (2017). Perbandingan Model Bisnis Perusahaan Jaringan Transportasi Di Indonesia Dalam Perspektif Platform Design Toolkit. V.2. TE, 6(2), 188.

Wuest, M. A. K. (2019). Upgradable product-service systems: Implications for business model components. Journal Procedia, 8(1), 768-773. https//doi.org/10.1016/j.procir.2019.01.091 
Almun Wakhida Candra: Transformasi Model Bisnis... 277

Yusar Sagara, M. A. P. (2016). Penguatan Ekonomi Kerakyatan Melalui Baitul Mal Tanwil ( Bmt ) Sebagai Balai Usaha Mandiri Rakyat Terpadu ( Bumrt ). Social Science Education Journal, 3(1), 81-91. https//doi.org/10.15408/sd.v3i1.4178.Permalink/DOI

Zaliluddin, D. (2016). Sistem Informasi Simpan Pinjam Koperasi BMT Baburahman dengan Menggunakan Visual Basic. Jurnal Informasi Technology, 2(1), 1-4. 